JUURNAL

of Health Inequalities

\title{
Towards systematic evaluation of the European Code Against Cancer. Dissemination of the Code in Poland
}

\author{
Kinga Janik-Koncewicz ${ }^{1,2}$, David Ritchie ${ }^{3}$, Urszula Blicharz ${ }^{4}$, Witold A. Zatoński1 ${ }^{1,5}$ \\ 'Health Promotion Foundation, Nadarzyn, Poland \\ ${ }^{2}$ Doctor of Philosophy (PhD) Candidate, University of Aberdeen, UK \\ ${ }^{3}$ Association of European Cancer Leagues (ECL), Brussels, Belgium \\ ${ }^{4}$ Center for Education Development, Warsaw, Poland \\ ${ }^{5}$ Medical University, Wrocław, Poland
}

\begin{abstract}
Cancer is one of the main causes of premature deaths worldwide. Because of that the aspect of prevention and treatment of cancer is a major public health issue. It is also a huge challenge for the healthcare system in Poland and other European countries.

In the 1980s the struggle with cancer in European population was recognized as one of the most important goals. That's why on the initiative of the European Commission the European Code Against Cancer was created. Nowadays, the fourth version of the Code has been disseminated. The Code is a set of the twelve practical recommendations, which anyone can use without a need for special skills or the use of specialist advice. The evidence-based recommendations are promoting healthy lifestyle, healthy behaviours and above all, they concern actions aimed at reducing exposure to tens of carcinogens from tobacco smoke and carcinogens from other sources, changes in eating habits, increased physical activity, and increased knowledge of early cancer diagnosis and treatment.

One of the principal activities of the Association of European Cancer Leagues (ECL) has been regularly monitoring the dissemination activities and knowledge on the Code in European countries. For example, dissemination of the Code in Poland within the National Cancer Control Programme in years 2006-2015 led to significant increase in people's awareness and improvement in health behaviours. ECL's venture and Polish experience lead to the statement that the Code is undoubtedly one of the most important and effective instrument in the fight against cancer in Europe.
\end{abstract}

KEY WORDS: European Code Against Cancer, Poland, health literacy, cancer primary prevention.

ADDRESS FOR CORRESPONDENCE: Kinga Janik-Koncewicz, Health Promotion Foundation, 51 Mszczonowska Street, 05-830 Nadarzyn, Poland, phone: +48 2237800 22, e-mail: biuro@promocjazdrowia.pl

\section{INTRODUCTION}

The European Code Against Cancer (ECAC, the Code) is an initiative of the European Commission aimed at building health literacy to reduce the risk of cancer. The Code is a set of recommendations promoting healthy behaviours and healthy lifestyle, and above all, they concern actions aimed at reducing exposure to tens of carcinogens from tobacco smoke and carcinogens from other sources, changes in eating habits, increased physical activity, and increased knowledge of early cancer diagnosis and treatment.

The Code was created on the initiative of the European Commission, which in the 1980s recognized the struggle with cancer in European population as one of the most important goals. This publication was guided by the idea of drawing public attention and sensitising it to the risks of cancer occurred in European Union countries, and thus also in Poland. 


\section{HISTORY OF THE CODE}

In the beginning of 1980s two scientists, Sir Richard Doll and Sir Richard Peto (knighted by Queen Elizabeth in 1999) created fundamental work on the causes of the cancer [1], which had become a cause of long-term discussion about methods of the fight against cancer. This report highlighted that achieving progress in cancer control cannot be related to cancer cure only but must include cancer literacy, building health behaviours and attitudes, and primary and secondary prevention.

In 1980s, a dramatic increase in incidence of cancer was observed in Europe. President Mitterrand, who suffered then from cancer initiated calling the European Cancer Expert Committee from the government representatives of the European Union member states in Milan in 1985. One of the first important results of Committee's work was preparing the first draft of the Code. The underlying message of this initiative was the growing number of morbidity and mortality from malignant neoplasms in Europe, and its main aim was to reduce the number of cancer deaths from $1,000,000$ to 850,000 (by 15\%) through primary prevention (with particular emphasis on reducing exposure to tobacco smoke), screening, and educational activities. To create a strategy to achieve this goal, the European Commission approved the first edition of the Code in 1987. In 1994, the European Commission invited the European School of Oncology to create a team of international experts and to review the recommendations of that time and to develop the updated second version of the Code [2]. First authors were among others Professor Umberto Veronesi and Professor Peter Boyle from Milan. After accession of the new member countries to the European Union, which resulted in the increase of the European population and its diversity in terms of behaviour related to lifestyle and risk of disease, in 2003 the third, updated edition of the Code was published [3].

\section{THIRD EDITION OF THE CODE IN POLAND}

The third edition of the Code was published in 2003 in the scientific journal "Annals of Oncology" [3], and Professor Witold Zatoński was one of co-authors. The Health Promotion Foundation began to popularize and implement the provisions of the Code in Poland. Next, the Code was entered as the main element of the activities in the implementation of the tasks of the National Program of Cancer Control named Primary Prevention of Cancers resulted from the postulate of Polish oncologists and organizations associating cancer patients. It has been implemented by the Maria Skłodowska-Curie Memorial Cancer Centre and Institute of Oncology in Warsaw since 2006. The implementation and financing of the Programme was undertaken by the Polish parliament (the parliament bill was adopted on $1^{\text {st } J u l y ~ 2005) . ~}$ Both the Code and the National Programme were to contribute to decrease cancer incidence and also to build health competence in Polish population.
In order to implement the Code, the team led by Professor Zatoński developed its Polish language version and adapted its content to the Polish social and cultural circumstances. Every oncologist in Poland received the Code with the journal "Nowotwory. Journal of Oncology", and every doctor in Poland received a book edition of the Code with the medical newspaper "Gazeta Lekarska". The Code was further disseminated in the health care environment among others through regional oncology centres, hospitals, sanitary-epidemiological stations and medical colleges. The Code became a part of the post-graduate training of doctors. An abbreviated, simplified version of the Code for the adult population, as well as comics for children and adolescents were developed. The Code was promoted through various types of information channels, including television, radio, press and websites. Various press conferences, educational workshops for journalists and media campaigns were organized. Training and scientific conferences for the medical environment (doctors, nurses and others) were conducted throughout the country.

A special role was played by the programme "School promoting the recommendations of the European Code Against Cancer". It was created and firstly implemented in the Małopolska Voivodeship by Urszula Blicharz (Director of the Regional Education office in Tarnów) and Professor Leszek Kołodziejski and Dr Zdzisław Wolak (Provincial Hospital of St. Luke in Tarnów). The programme was devoted to the education of children and adolescents in the range of primary cancer prevention by promoting a healthy lifestyle. The basis of the programme was the assumption that the school is an extremely important place in the children lives, in which the right attitudes and pro-health behaviours are shaped. Therefore, conducting systematic education in the field of prevention of cancer but also encouraging to various types of activities in this area at school, is necessary for building the health of the population. In addition to direct education of kindergarten and primary school students in the form of lectures, various activities were organized to encourage young people to lead a healthy lifestyle, in particular workshops, exhibitions, happenings, tournaments, fairs, knowledge contests and others during which educational materials were distributed. The lectures were conducted by prepared for this purpose educators.

School activities in local communities were supported by various media and happening actions promoting not smoking tobacco (including the World No Tobacco Day and World No Smoking Day), adequate eating habits (vegetables and fruits 5 times a day), increased physical activity (I walk, I run - so I am), and devoted to education on risk factors and early signs of skin cancer and others. As a result in the Małopolska voivodship, approximately $80 \%$ of schools, 20,000 teachers, 300,000 students and 20,000 inhabitants of the local community were involved in realisation of the programme for children. 


\section{FOURTH EDITION OF THE CODE}

The current, fourth edition of the European Code Against Cancer [4] is a set of the twelve practical recommendations, which anyone can use without a need for special skills or the use of specialist advice. It's an initiative to inform people about actions they can take for themselves, or their families, to reduce their risk of cancer. The Code assumes that the more recommendations will be implemented, the lower the risk of cancer would be. A group of scientists developing recommendations estimated that almost half of cancer deaths in Europe could be avoided if everyone followed the recommendations of the Code $[5,6]$.

The fourth edition of the Code comprised of 12 evidence-based recommendations, which the public can understand and follow without any special skills or advice. It draws attention to the fact that smoking is the most common cause of cancer in European Union countries. Overweight or obesity, bad nutritional habits, lack of physical activity, drinking alcohol, or an unhealthy lifestyle, is a possible cause for the development of cancer. Similarly, exposure to sunlight radiation and some other types of ionizing radiation (for example radon), as well as exposure to carcinogens in the workplace plus certain infections (including those caused by the Hepatitis virus, Human papillomavirus or Helicobacter pylori) are important factors responsible for the formation of tumours. The greater the risk of cancer development, the greater the exposure to the above-mentioned factors (duration, frequency and the level of exposure).

\section{RESULTS OF LUNG CANCER FIGHT IN POLAND}

In Poland, the fight against cancer has begun to bear fruit in recent decades. A particular success in years 2006-2015 was the reduction in exposure to carcinogenic factors from tobacco smoke (active and passive smoking). The annual consumption of cigarettes has decreased from 69 billion in 2006 to around 44 billion in 2015, and prevalence of smoking from 39\% in 2006 to $28 \%$ in 2014 in men, and from $22 \%$ to $19 \%$, respectively in women. The reduction of the exposure to tobacco smoke carcinogens in Poland is still the cause of continued sustainable decline in the incidence and mortality rates due to lung cancer in middle-aged men. Also, for the first time after the World War II, the incidence and mortality rates began to decline in group of middle-aged women (see Lung cancer mortality decline among middle-aged men and women in Poland and the UK, pp. 123-126). The decline in incidence and mortality rates from lung cancer in Poland is one of the fastest in Europe [8]. The effectiveness of the fight against lung cancer in Poland is considered a showcase for the effectiveness of smoking control.

BOX 1. European Code Against Cancer Fourth Edition [7]

Twelve ways to reduce your cancer risk:

1. Do not smoke. Do not use any form of tobacco.

2. Make your home smoke free. Support smoke-free policies in your workplace.

3. Take action to be a healthy body weight.

4. Be physically active in everyday life. Limit the time you spend sitting.

5. Have a healthy diet:

- Eat plenty of whole grains, pulses, vegetables and fruits.

- Limit high-calorie foods (foods high in sugar or fat) and avoid sugary drinks.

- Avoid processed meat; limit red meat and foods high in salt.

6. If you drink alcohol of any type, limit your intake. Not drinking alcohol is better for cancer prevention.

7. Avoid too much sun, especially for children. Use sun protection. Do not use sunbeds.

8. In the workplace, protect yourself against cancer-causing substances by following health and safety instructions.

9. Find out if you are exposed to radiation from naturally high radon levels in your home. Take action to reduce high radon levels.

10. For women:

- Breastfeeding reduces the mother's cancer risk. If you can, breastfeed your baby.

- Hormone replacement therapy (HRT) increases the risk of certain cancers.

- Limit use of HRT.

11. Ensure your children take part in vaccination programmes for:

- Hepatitis B (for newborns).

- Human papillomavirus (HPV) (for girls).

12. Take part in organised cancer screening programmes for:

- Bowel cancer (men and women).

- Breast cancer (women).

- Cervical cancer (women).

The European Code Against Cancer focuses on actions that individual citizens can take to help prevent cancer. Successful cancer prevention requires these individual actions to be supported by governmental policies and actions. 
It must be noted that we are still at the beginning of the road to success in Poland and the problem of premature mortality due to cancer persists. It is therefore crucial to reduce the exposure of carcinogens from tobacco smoke and the spread of population screening programs to detect cervical, breast and colorectal cancers.

\section{TOWARDS A SYSTEMATIC EVALUATION OF THE EUROPEAN CODE AGAINST CANCER}

Following the publication of the $4^{\text {th }}$ edition of the ECAC, the Association of European Cancer Leagues (ECL) received core funding from the European Commission via the $3^{\text {rd }} \mathrm{EU}$ health programme 2014-2020 to support the dissemination of the latest version of the ECAC through close cooperation with cancer leagues at the national and regional level in Europe.

One of the principal activities to disseminate the ECAC has been the organisation of thematic workshops for the representatives of cancer leagues and relevant stakeholders. These workshops aim to: facilitate the sharing of experiences related to the implementation of the ECAC; identify common barriers in cancer prevention; and discuss possible solutions to improve the overall dissemination.

The latest workshop on the dissemination of the ECAC, which was held on 27 September 2017 in Copenhagen at the headquarters of the Danish Cancer Society, reflected on the impact of the ECAC, and considered possible methodologies to evaluate the ECAC. The following paragraphs provide a concise summary of the proceedings, indicating the possible actions that can be taken to follow-up on the issues arising from the workshop.

The workshop was structured around two distinct sessions. The first session was dedicated to the interventions of specially invited experts: Professor Witold Zatonski (Health Promotion Foundation, Nadarzyn, Poland), and Dr Hans Storm of the Danish Cancer Society, were invited to share their experiences as members of the scientific committees for the current and previous editions of the ECAC, and to demonstrate how ECAC had been promot- ed in their respective countries. In addition, Mr Thomas Krogh also of the Danish Cancer Society, was invited to inform participants of the current approach to the ECAC taken by the Danish Cancer Society. The second session focused on small group discussions reflecting on participants' own experiences of communicating and applying the ECAC, and taking into account the contributions of the experts from the previous session. In total, more than 30 participants were attended the workshop including invited stakeholders, such as the International Agency for Research on Cancer (IARC), and representatives covering 14 different cancer leagues.

Participants at the workshop were presented with the problem analysis stating that after almost 30 years of dissemination, little had been done to determine the impact of the ECAC. Consequently, the aim of the workshop was to initiate a discussion on the possible requirements for a systematic evaluation of the impact of the ECAC. The specific objectives were to identify key issues for such an evaluation, and to appreciate the lessons that can be learned from how the previous editions of the ECAC were promoted.

Two approaches fundamental to an evaluation of the impact of the ECAC emerged from the presentations and discussions of the workshop: that which is directed at understanding how the ECAC can improve the cancer literacy of individuals, and that which proposes to examine the ECAC in terms of its impact on the development of interventions, thereby encouraging action at the population level. The discussion weighed the relative importance of various target groups, but no clear consensus could be reached at this early stage. Therefore, further work is required on this issue to systematically arrive at a consensus amongst experts and practitioners familiar with the implementation of the ECAC.

Feedback resulting from the small group discussions stressed that identifying certain goals, for dissemination and uptake at the national level, would be one valuable action to take towards developing an evaluation of the ECAC. The identification of such goals could follow the

\section{BOX 2. Selected articles published on European Code against Cancer}

Minozzi S, Armaroli P, Espina C, et al. European Code against Cancer, $4^{\text {th }}$ Edition. Process of reviewing the scientific evidence and revising the recommendations. Cancer Epidemiol 2015; 39 (Suppl 1): S11-S19.

Döbrőssy L, Cornides Á. European Code against Cancer: 12 ways to reduce your cancer risk. Orv Hetil 2016; 157: 451-460.

Boyle $\mathrm{P}$, d'Onofrio A, Maisonneuve $\mathrm{P}$, et al. Measuring progress against cancer in Europe: Has the $15 \%$ decline targeted for 2000 come about? Ann Oncol 2003; 14: 1312-1325.

López ML, del Valle MO, Cueto A. Knowledge of the European Code against Cancer in sixth-form pupils and teachers in Asturias (Spain). Eur J Cancer Prev 1994; 3: 207-213.

López ML, García-Cueto E, Fernández JM, et al. Validation of a questionnaire to evaluate the attitude towards primary prevention advice from the European code against cancer. Eur J Cancer Prev 2003; 12: 157-164.

López ML, Iglesias JM, García Cueto E, et al. Attitude to primary prevention advice of the European Code against cancer in relatives of cancer patients: Implications for the development of preventive programmes. Psicothema 2006; 18: 478-484.

Pérula-de-Torres LÁ, Marzó-Castillejo M, Ranchal-Sánchez A, et al. European Code Against Cancer: What does the Spanish population know and think about its recommendations? Eur J Cancer Prev 2015; 24: 69-75. 
example of the Danish Cancer Society whereby national goals for cancer prevention have been established based on the 12 recommendations of the ECAC.

In terms of follow-up, a meeting of invited experts covering the scientific committees of the current and former editions of the ECAC, plus selected practitioners familiar with its local and national implementation, will take place in early 2018. This meeting will build on the viewpoints established in September 2017, and seek to build consensus for a systematic evaluation of the ECAC.

\section{SURVEY ON AWARENESS OF THE CODE}

The Association of European Cancer Leagues has been regularly monitoring the knowledge on the Code in European countries. The latest survey in Poland was conducted between $18^{\text {th }}$ and $24^{\text {th }}$ October 2017 by YouGov Plc using an online questionnaire in sample of approximately 1,000 Polish adults. The results of the survey have been weighted and are representative of Polish adults aged $18+$ years.

The study showed that $80 \%$ of respondents think people can reduce their risk of cancer by making lifestyle changes. Seventy four percent of Poles say it is fairly or very likely they would make changes to their lifestyle in order to reduce their cancer risk, while only $3 \%$ answered "not at all likely". Asked if they had heard of the ECAC, 79\% answered "yes" and 21\% "no". More than half of respondents reported learning something new about cancer prevention from reading the $12 \mathrm{rec}$ ommendations of the Code; $33 \%$ did not.

\section{CONCLUSIONS}

The aspect of prevention and treatment of cancer is a major public health issue, but also a huge challenge for the healthcare system in Poland and other European countries as cancer is the main cause of premature deaths (before the age of 65). Treatment is just one of the possibilities that medicine offers. Cancers can be and must be prevented. Primary and secondary prevention is intended to serve this task.

Dissemination of the Code in Poland within the National Cancer Control Programme led to significant increase in people's awareness and improvement in health behaviours and can be used as an example for other countries. Unfortunately, we are still at the beginning of the cancer fight in Poland and in many areas in the end of Europe. Therefore, the decision to terminate the National Cancer Control Programme in Poland is incomprehensible and requires immediate resumption. The ECAC is undoubtedly one of the most important and effective instruments in cancer fight in Europe.

\section{ACKNOWLEDGEMENTS}

Authors would like to acknowledge the invaluable assistance of Mr. Scott Thompson in the preparation of the final version of this article.

\section{DISCLOSURE}

Authors report no conflict of interest.

\section{References}

1. Doll R, Peto R. The causes of cancer: quantitative estimates of avoidable risks of cancer in the United States today. J Natl Cancer Inst 1981; 66: 1191-1308.

2. Boyle P, Veronesi U, Tubiana M, et al. European School of Oncology Advisory Report to the European Commission for the "Europe Against Cancer Programme" European Code Against Cancer. Eur J Cancer 1995; 31A: 1395-1405.

3. Boyle P, Autier P, Bartelink H, Baselga J, Boffetta P, Burn J, Burns HJ, Christensen L, Denis L, Dicato M, Diehl V, Doll R, Franceschi S, Gillis CR, Gray N, Griciute L, Hackshaw A, Kasler M, Kogevinas M, Kvinnsland S, La Vecchia C, Levi F, McVie JG, Maisonneuve P, Martin-Moreno JM, Bishop JN, Oleari F, Perrin P, Quinn M, Richards M, Ringborg U, Scully C, Siracka E, Storm H, Tubiana M, Tursz T, Veronesi U, Wald N, Weber W, Zaridze DG, Zatonski W, zur Hausen H. European Code Against Cancer and scientific justification: third version. Ann Oncol 2003; 14: 973-1005.

4. Schüz J, Espina C, Villain P, Herrero R, Leon ME, Minozzi S, Romieu I, Segnan N, Wardle J, Wiseman M, Belardelli F, Bettcher D, Cavalli F, Galea G, Lenoir G, Martin-Moreno JM, Nicula FA, Olsen JH, Patnick J, Primic-Zakelj M, Puska P, van Leeuwen FE, Wiestler O, Zatonski W; Working Groups of Scientific Experts. European Code against Cancer 4th Edition: 12 ways to reduce your cancer risk. Cancer Epidemiol 2015; 39 (Suppl 1): S1-S10.

5. Parkin DM, Boyd L, Walker LC. The fraction of cancer attributable to lifestyle and environmental factors in the UK in 2010. Br J Cancer 2011; 105 (Suppl): S77-81.

6. Danaei G, Vander Hoorn S, Lopez AD, et al. Comparative Risk Assessment collaborating group (Cancers). Causes of cancer in the world: comparative risk assessment of nine behavioural and environmental risk factors. Lancet 2005; 366: 1784-1793.

7. European Code Against Cancer. 12 ways to reduce your cancer risk. Available from: https://cancer-code-europe.iarc.fr/index. php/en/ (accessed: 6 September 2017).

8. GBD 2015 Tobacco Collaborators. Smoking prevalence and attributable disease burden in 195 countries and territories, 1990-2015: a systematic analysis from the Global Burden of Disease Study 2015. Lancet 2017; 389: 1885-1906.

\section{AUTHORS' CONTRIBUTIONS}

KJK and DR prepared the article. All authors contributed to preparing the concept and the final version of the publication. 